Ann. rheum. Dis. (1957), 16, 101.

\title{
NUMERICAL METHOD OF EVALUATING THE STATUS OF RHEUMATOID ARTHRITIS*
}

\author{
BY
}

\author{
JOHN LANSBURY \\ Philadelphia, Pa
}

In the field of rheumatism, one of the most pressing needs is for a standardized, objective, and reliable index of the activity of rheumatoid arthritis which, while not taking into account all the manifold manifestations of the disease, will nevertheless provide a trustworthy guide both to its course in individual cases and to therapeutic responses in multi-clinic trials. In this paper we present a summary of our previous work on the development of a Systemic Index which, we believe, fulfills this function. We also give an outline of the Articular

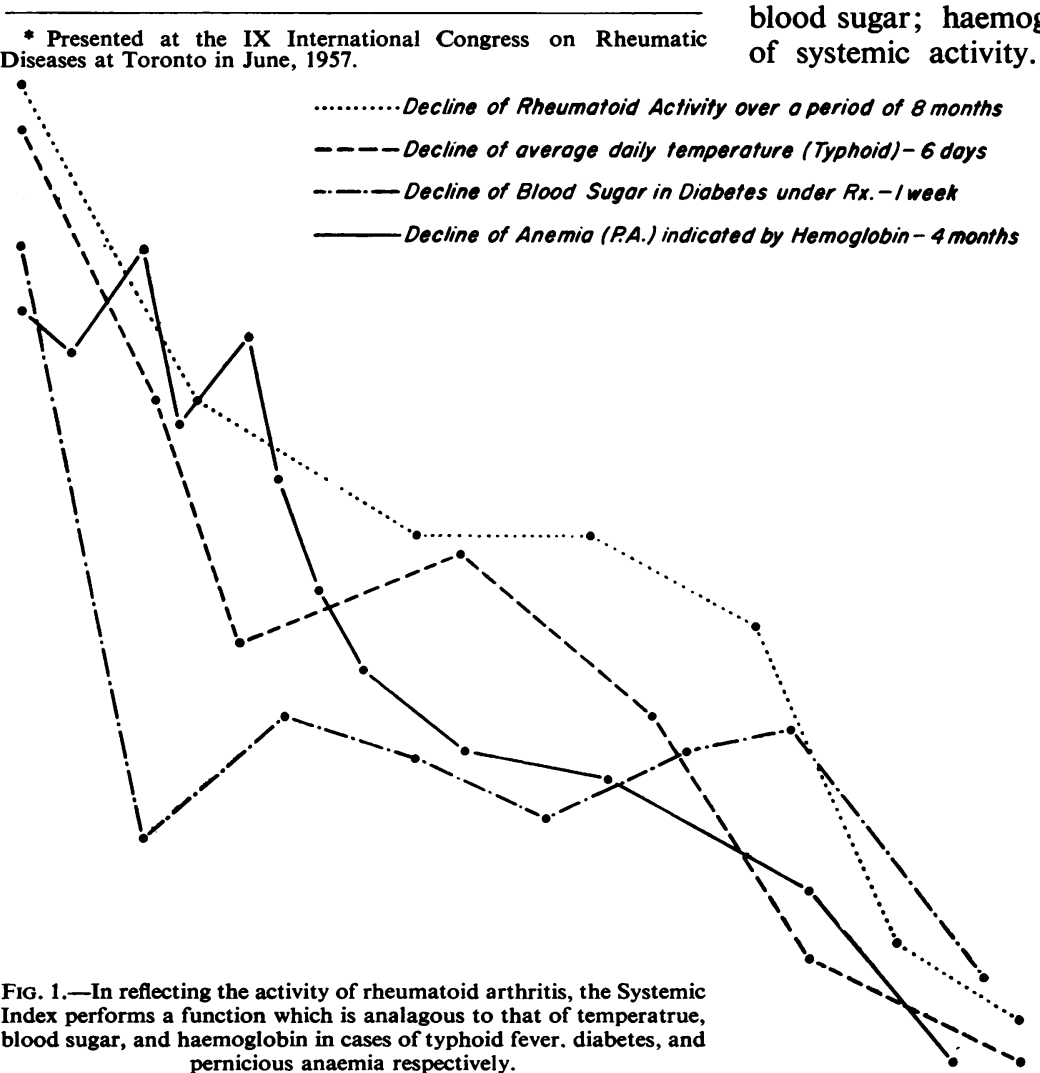

Index by which various joint findings may be summed up numerically.

\section{Systemic Index}

The time-honoured principle of using one measurable facet of a disease as a guide to its clinical course is illustrated in Fig. 1, which portrays the progressive trends towards "remission" or "cure" in cases of typhoid fever, diabetes mellitus, pernicious anaemia, and rheumatoid arthritis. The curves are based respectively on average daily temperature; fasting blood sugar; haemoglobin per cent., and the index Naturally, these individual items do not tell us about the structural changes wrought by the "activity" of the disease in question. Thus, we cannot tell from the fever chart alone that the typhoid fever patient is about to have an intestinal perforation; nor can we infer from the fasting blood sugar that the diabetic patient is suffering from diabetic neuritis or gangrene; nor does the haemoglobin level inform us that the pernicious anaemia patient is suffering from postero-lateral sclerosis of the spinal cord; nor can we infer from the Systemic Index the extent of crippling in a case of rheumatoid arthritis.

Nevertheless, despite their monosignificance, these measurable facets of the three non-rheumatic diseases are an indispensable guide to therapy and to the general trend of disease "activity". 
The Systemic Index, although composite, likewise serves as a guide to the activity of rheumatoid arthritis.

It has been objected that the Systemic Index cannot distinguish between a spontaneous and a drug-induced remission. But this is no argument against its usefulness, for such an objection applied to other diseases, would lead us to the ridiculous position of claiming, for instance, that blood sugar determinations are misleading in a case of diabetes mellitus because the vascular lesions may be slowly deteriorating despite the normalization of glucose values; or that the heart rate is not worth recording in a case of cardiac disease because, although controlled by digitalis, the underlying disease is getting progressively worse.

On the other hand, acceptance of the Systemic Index as a measure of "activity" in no way lessens the necessity for also observing slowly progressive structural changes. Indeed, where the inflammatory joint changes are themselves suppressed by powerful anti-inflammatory agents, the ultimate progress of the disease may have to be judged by serial $x$-rays, just as the slow advance of cardiac disease may be judged by the gradual enlargement of the cardiac silhouette as seen on the $x$-ray film.

The important thing is that the "activity" of the disease should be kept separate from the gross structural changes which are the result of that activity. (The present American Rheumatism Association classification was the first, we believe, to make this distinction.) In our scheme, the Systemic Index and the Articular Index keep these two aspects of the disease as separate as is possible.

\section{Basis of the Systemic Index}

(1) Separation of activity from deformity by relying only on systemic (non-articular) observations.

(2) Selection of those systemic manifestations which can be objectively and quantitatively observed and which are present in the great majority of cases at all stages of active disease.

(3) Summation of the values for each item by converting them to percentages of their average magnitudes in untreated patients.

Items meeting the above requirements are:

(i) Duration of morning stiffness,

(ii) Hours after rising before onset of fatigue,

(iii) Number of aspirin tablets needed per day to control pain,

(iv) Grip strength,

(v) Erythrocyte sedimentation rate.
Other systemic manifestations such as fever, weight loss, anaemia, diurnal jelling after rest, and number of hours of rest and/or motion pain have not been used, either because they occur so infrequently that they would only dilute the values of the five chosen items, or because they cannot readily be referred to a normal base line. Many of them are nevertheless worth recording and could be used in a multi-clinic test of a drug where they could be mathematically treated at leisure.

The reader may at this point object that stiffness, fatigue, and aspirin consumption are purely subjective, but we may point out that patients are concerned with the intensity of their stiffness, fatigue, and pain but have no strong feelings about duration, time of onset, or number of tablets. Their statements are therefore unhampered by emotion and may thus be considered objective. Information gathered by two people, rather than one, is not automatically subjective or inaccurate.

We do not yet know in what way, to what extent, or how promptly each item reflects the activity of the disease, but we can be certain that, when any one of them definitely changes for better or for worse, the activity of the disease is also, in this respect, better or worse. A comprehensive statistical analysis by Mainland (1956) showed that no single index wass highly correlated with any other, or with the average of the other four. This points to the desirability of using all five indices and to a need for discovering more indices, if possible. The real question seems to be not whether each index is accurate, but whether the five now in use constitute an adequate sample of the manifold manifestations of the disease.

Fig. 2 (opposite) shows, in an ideal fashion, the parallel manner in which the indices declined as a patient went into a full clinical remission. This parallel type of decline suggests that such quantitative data cannot be forced into artificial grades or categories or dealt with on a "yes or no", "present or absent" basis, and must therefore be dealt with by a process of averaging as noted below.

\section{Method of Applying the Systemic Index}

(1) The Rubber Stamp.-It is imperative that at each patient-visit all five items be recorded, since the omission of even one item invalidates the Index. To guard against such omissions a rubber stamp listing all five items is impressed on the patient's chart at the time of each monthly evaluation.

(2) Duration of Morning Stiffness.-One should never ask the patient "How long are you stiff in the morning", but rather "What time do you get up in 


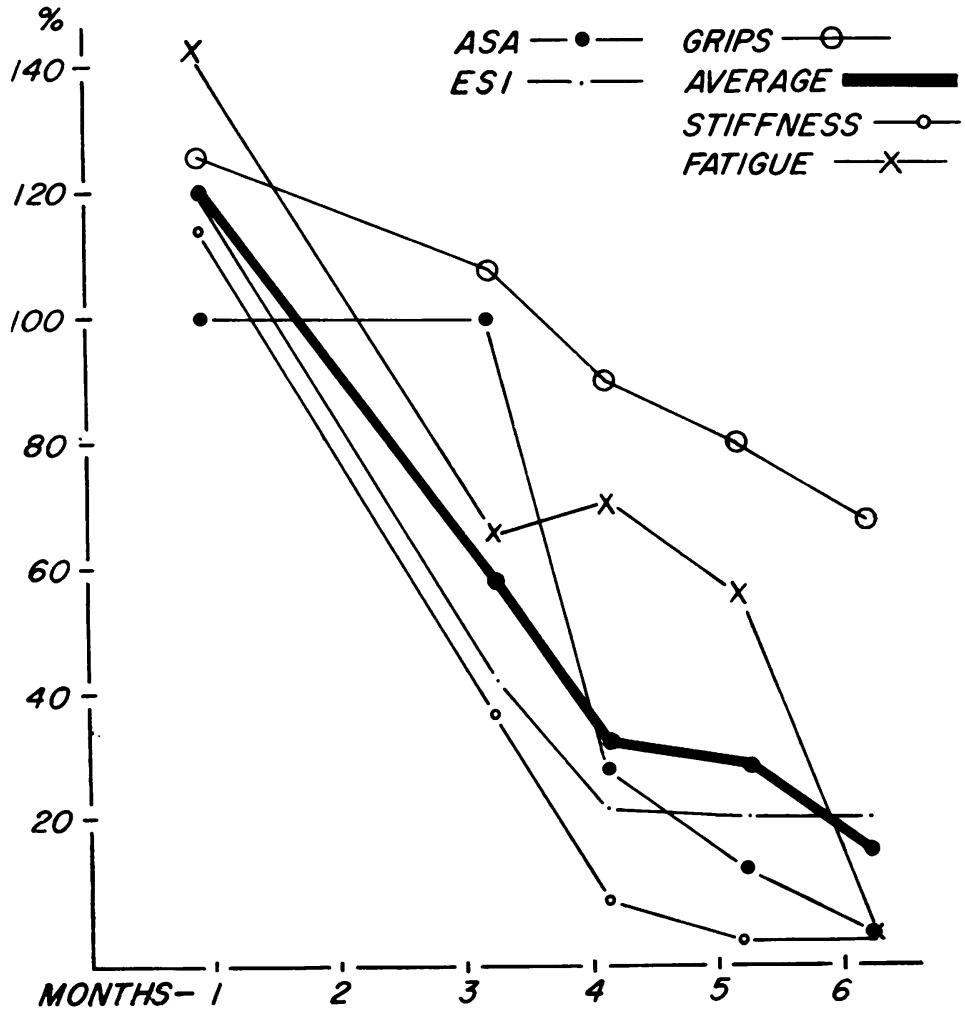

Fig. 2.-Items composing the Systemic Index decline in a more or less parallel fashion as the patient goes into remission, and are therefore dealt with by averaging rather than by assigning them to arbitrary grades.

the morning?", "Are you stiff?" If so, "By what time does the stiffness wear off", or "By what time do you limber up?" The observer then makes the calculation of hours of morning stiffness.

(3) Hours after Rising before Onset of Fatigue.This is more difficult to elicit and some crossquestioning may be necessary. The hour of rising has already been established. One therefore asks "Are you tired when you get up in the morning?" If the answer is "Yes", this represents the maximum degree of fatigue, but one must immediately distinguish between neurotic fatigue, fatigue due to poor sleep, and true rheumatoid fatigue. Neurotic fatigue is a lack of desire for action and, in our experience, occurs infrequently in rheumatoid patients. Fatigue due to lack of sleep wears off in an hour or so, but fatigue due to rheumatoid arthritis does not. With this question settled, one then asks (if the patient is not fatigued on rising), "By what time of day do you feel tired?" It is important to distinguish between true fatigue and a desire to rest because of foot-pain.
(4) Aspirin Required to relieve Pain.-The patient should have at least one week's trial of a prescribed dose of aspirin, eight to twelve tablets per day, so that he may feel its benefit and not refuse to take it because it is "bad for the heart", etc. He is then instructed to take it ad lib for relief of pain. When near a remission, many patients take one or two aspirin tablets on retiring, as a sedative. This, naturally, does not count. One must also be sure that the patient is not taking aspirin just from habit, but such distinctions can easily be made by questioning the patient. Cohen and Calkins (1957) used a weekly record of the daily aspirin consumption and were favourably impressed by the accuracy of the average daily values.

(5) Measurement of Grip Strength.-For this we prefer an ordinary, rather than a pediatric blood-pressure cuff, and a standard mercury manometer blood-pressure apparatus which registers to $300 \mathrm{~mm}$. $\mathrm{Hg}$. The cuff is folded twice and the system inflated to $20 \mathrm{~mm}$. $\mathrm{Hg}$, the doctor then squeezes the bag and shows the patient how to "ring the bell". With the mercury column in full view the patient then makes three tries to "beat the doctor". The highest reading for each hand is observed, and the average of the two recorded. In new patients it is well to try a fairly tightly-bound as well as a loosely-bound cuff, to be sure that one is not definitely superior to the other. Observations should be made at the same time of day. Where advanced deformities prevent an adequate grip on the cuff this item is rejected.

(6) Erythrocyte Sedimentation Rate.-We believe that the maximum fall of erythrocytes in any 5-minute period, as it occurs in the Cutler method over a 30-minute period, provides the best index of red cell sedimentation. Tentatively, we have also admitted the one hour reading by the Westergren method although a small study indicated considerably less uniformity in its results. (The Rourke-Ernstene method should give approximately the same information as the Cutler method. The Wintrobe erythrocyte sedimentation rate we have found quite unsatisfactory, as have many of our colleagues.) 
(7) Summation.-The five items of basic information having been collected, the values are converted to percentages by referring to Table I. The sum of these is divided by the number of items (five, usually) to obtain the Systemic Index. The index should be charted on ordinary graph paper from month to month so that trends can be visualized.

(If one or more items are unobtainable, the average of the remainder may still be used as a guide to the course of the disease in individual patients, but the figure so obtained should not be regarded as being on the same scale as the full index of five components, and so should not be incorporated in a study of group responses to therapy.)

Summation is a key step in any process of evaluation because, either consciously or unconsciously, it is always carried out no matter what method of evaluation is being used. Un-itemized and unstandardized types of summation used to classify activity into categories such as "very active", "moderately active", or "inactive", seem too poorly defined and too subjective to be used in collecting data from multiple observers. By comparison, the Systemic Index permits summation to be made in a standardized, objective manner.

\section{Conclusions as to the Value of the Systemic Index}

We have been using the Systemic Index for over 2 years and now have records of more than 2,000 observations on over 400 patient-visits. In more than thirty cases the Index has been charted in graphic form for periods ranging from a few months

TABLE I

CONVERSION OF OBSERVED VALUES TO PERCENTAGE EQUIVALENTS

\begin{tabular}{|c|c|c|c|c|c|c|c|c|c|c|c|c|}
\hline \multirow{2}{*}{\multicolumn{2}{|c|}{$\begin{array}{l}\text { Duration of } \\
\text { Morning Stiffness }\end{array}$}} & \multirow{2}{*}{\multicolumn{2}{|c|}{$\begin{array}{l}\text { Onset of Fatigue } \\
\text { After Rising }\end{array}$}} & \multirow{2}{*}{\multicolumn{2}{|c|}{ Aspirin }} & \multirow{2}{*}{\multicolumn{3}{|c|}{ Grip Weakness }} & \multicolumn{4}{|c|}{ Erythrocyte Sedimentation Rate } \\
\hline & & & & & & & & & Cut & ler & Wes & rgren \\
\hline \multirow[b]{2}{*}{ Min. } & \multirow[b]{2}{*}{ Per cent. } & \multirow[b]{2}{*}{ Hrs } & \multirow[b]{2}{*}{ Per cent. } & \multirow{2}{*}{$\begin{array}{l}\text { Tabs } \\
\text { per day }\end{array}$} & \multirow[b]{2}{*}{ Per cent. } & \multirow[b]{2}{*}{$\mathrm{mm} . \mathbf{H g}$} & \multicolumn{2}{|c|}{ Per cent. } & \multirow[b]{2}{*}{$\mathrm{mm} . / 5 \mathrm{~min}}$. & \multirow[b]{2}{*}{ Per cent. } & \multirow[b]{2}{*}{$\mathrm{mm} . / \mathrm{hr}$} & \multirow[b]{2}{*}{ Per cent. } \\
\hline & & & & & & & Male & Female & & & & \\
\hline $\begin{array}{r}5 \\
10 \\
15 \\
20 \\
30 \\
45 \\
\text { Hrs } \\
1 \cdot 0 \\
1 \cdot 5 \\
2 \cdot 0 \\
2 \cdot 5 \\
3 \cdot 0 \\
3 \cdot 5 \\
4 \cdot 0 \\
4 \cdot 5 \\
5 \cdot 0 \\
5 \cdot 5 \\
6.0 \\
6 \cdot 5 \\
7.0 \\
7.5 \\
8.0\end{array}$ & $\begin{array}{r}2 \\
5 \\
7 \\
9 \\
14 \\
21 \\
29 \\
43 \\
57 \\
72 \\
86 \\
100 \\
114 \\
129 \\
143 \\
157 \\
171 \\
186 \\
200 \\
214 \\
229\end{array}$ & $\begin{array}{l}8 \cdot 0 \\
7 \cdot 5 \\
7 \cdot 0 \\
6 \cdot 5 \\
6 \cdot 0 \\
5 \cdot 5 \\
5 \cdot 0 \\
4 \cdot 5 \\
4 \cdot 0 \\
3 \cdot 5 \\
3 \cdot 0 \\
2 \cdot 5 \\
2 \cdot 5 \\
1 \cdot 5 \\
1 \cdot 0 \\
0 \cdot 5 \\
0 \cdot 0\end{array}$ & $\begin{array}{r}0 \\
14 \\
29 \\
43 \\
57 \\
71 \\
86 \\
100 \\
114 \\
129 \\
143 \\
157 \\
171 \\
186 \\
200 \\
214 \\
229\end{array}$ & $\begin{array}{r}0 \\
1 \\
2 \\
3 \\
4 \\
5 \\
6 \\
7 \\
8 \\
9 \\
10 \\
11 \\
12 \\
13 \\
14 \\
15 \\
16 \\
17 \\
18 \\
19 \\
20 \\
21 \\
22 \\
23 \\
24 \\
25\end{array}$ & $\begin{array}{r}0 \\
12 \\
25 \\
37 \\
50 \\
62 \\
75 \\
87 \\
100 \\
112 \\
125 \\
137 \\
150 \\
162 \\
175 \\
187 \\
200 \\
212 \\
225 \\
237 \\
250 \\
262 \\
275 \\
287 \\
300 \\
312\end{array}$ & $\begin{array}{r}290 \\
280 \\
270 \\
260 \\
250 \\
240 \\
230 \\
220 \\
210 \\
200 \\
190 \\
180 \\
170 \\
160 \\
150 \\
140 \\
130 \\
120 \\
110 \\
100 \\
90 \\
80 \\
70 \\
60 \\
50 \\
40 \\
30 \\
20\end{array}$ & $\begin{array}{r}6 \\
12 \\
19 \\
25 \\
31 \\
37 \\
44 \\
50 \\
56 \\
62 \\
69 \\
75 \\
81 \\
87 \\
94 \\
100 \\
106 \\
112 \\
119 \\
125 \\
131 \\
137 \\
144 \\
150 \\
156 \\
162 \\
169 \\
175\end{array}$ & $\begin{array}{r}0 \\
0 \\
0 \\
0 \\
6 \\
12 \\
19 \\
25 \\
31 \\
37 \\
44 \\
50 \\
56 \\
62 \\
69 \\
75 \\
81 \\
87 \\
94 \\
100 \\
106 \\
112 \\
119 \\
125 \\
131 \\
137 \\
144 \\
150\end{array}$ & 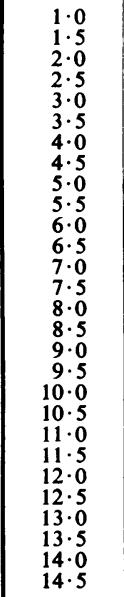 & $\begin{array}{r}0 \\
10 \\
20 \\
30 \\
40 \\
50 \\
60 \\
70 \\
80 \\
90 \\
100 \\
110 \\
120 \\
130 \\
140 \\
150 \\
160 \\
170 \\
180 \\
190 \\
200 \\
210 \\
220 \\
230 \\
240 \\
250 \\
260 \\
270\end{array}$ & $\begin{array}{r}10 \\
15 \\
20 \\
25 \\
30 \\
35 \\
40 \\
45 \\
50 \\
55 \\
60 \\
65 \\
70 \\
75 \\
80 \\
85 \\
90 \\
95 \\
100 \\
105 \\
110 \\
115 \\
120 \\
125 \\
130 \\
135 \\
140 \\
145\end{array}$ & $\begin{array}{r}0 \\
8 \\
17 \\
25 \\
33 \\
42 \\
50 \\
58 \\
67 \\
75 \\
83 \\
92 \\
100 \\
108 \\
117 \\
125 \\
133 \\
142 \\
150 \\
158 \\
167 \\
175 \\
183 \\
192 \\
200 \\
208 \\
217 \\
225\end{array}$ \\
\hline
\end{tabular}

Reprinted, by kind permission of Lea and Febiger from The American Journal of the Medical Sciences, 232, 305 (1956) with the following modifications: The percentage values for grips have been arranged so that it is no longer necessary to deduct the $20 \mathrm{~mm}$. Hg used to inflate the cuff; haemoglobin values have been omitted.

Sample Calculation

\begin{tabular}{|c|c|c|c|c|c|}
\hline \multirow{2}{*}{\multicolumn{2}{|c|}{ Items Observed }} & \multicolumn{4}{|c|}{ Date } \\
\hline & & \multicolumn{2}{|c|}{ July, 1956} & \multicolumn{2}{|c|}{ March, 1957} \\
\hline $\begin{array}{l}\text { Duration of morning stiffness (hrs) } \\
\text { Onset of fatigue after rising (hrs) } \\
\text { Aspirin (tablets per day) . } \\
\text { Average maximum grips (mm. Hg) } \\
\text { Maximum erythrocyte sedimentation rate }\end{array}$ & 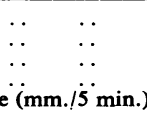 & $\begin{array}{r}4 \cdot 5 \\
3 \\
8 \\
60 \\
7\end{array}$ & $\begin{array}{l}129 \% \\
143 \% \\
100 \% \\
125 \% \\
120 \%\end{array}$ & $\begin{array}{r}0 \\
8 \\
0 \\
200 \\
2\end{array}$ & $\begin{array}{l}0 \% \\
0 \% \\
0 \% \\
37 \% \\
20 \%\end{array}$ \\
\hline $\begin{array}{l}\text { Sum of Percentages } \\
\text { Systemic Index (Divide Sum by } \ddot{5} \text { ) }\end{array}$ & $\cdots$ & & $\begin{array}{l}617 \\
123\end{array}$ & & $\begin{array}{l}57 \\
11\end{array}$ \\
\hline
\end{tabular}


to over 2 years (average 13 months). From these data we have drawn certain conclusions.

The method was applicable in about 90 per cent. of our patients. We feel certain that the Systemic Index, without joint findings, is capable of detecting a true clinical remission; moreover, it is a sensitive indicator, capable of registering values from 0 to over 200 per cent., thus detecting the widest swings in the activity of the disease.

When graphed at monthly intervals, the Index has proved a valuable guide to both treatment and prognosis and has permitted a study of exacerbating factors which would not otherwise have been detected. Fig. 3 illustrates the differences in trends of individual patients going into remission compared with those pursuing a more or less static course. From the point of view of accuracy, it seems to us that the Index compares more than favourably with other well-established procedures, such as, for instance, the basal metabolic rate in evaluating thyroid function. On the whole, patients

\section{CASES SHOWING NO IMPROVEMENT}

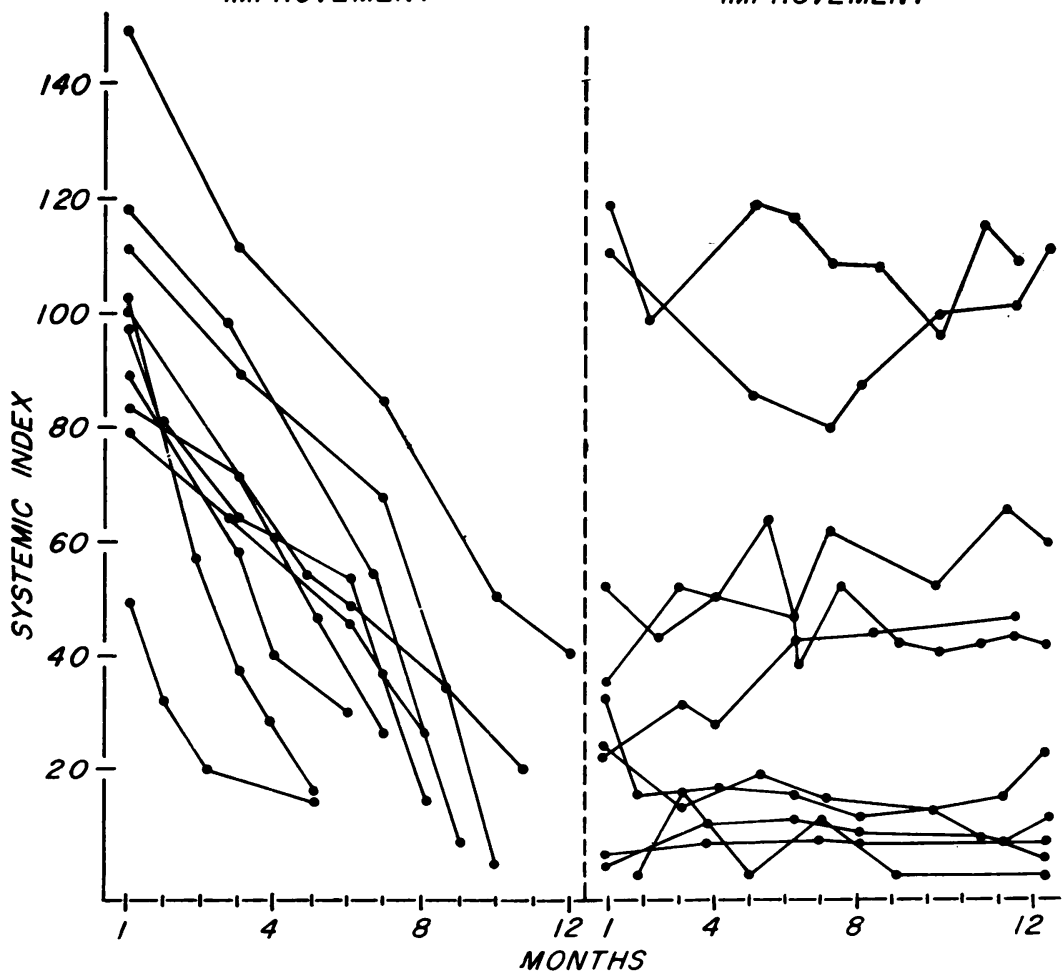

FIG. 3.-Two groups of ten cases of rheumatoid arthritis showing how the Systemic Index reflects the trends of activity. In each case the Index confirms the clinical impression of the observer. (Values of twenty or below would generally be classed as an excellent remission.) receiving steroid therapy register the most irregular courses. This is understandable, since a reduction of as little as $1.25 \mathrm{mg}$. meticorten per day may cause a significant rise in the Systemic Index.

Where the Systemic Index is used for drug testing in groups of patients, its various component items should be separately scrutinized, since a given drug might selectively affect certain items rather than all of them.

\section{Articular Index}

This is simply a device for estimating the total amount of arthritis. It is based on joint size as determined by the area of articulating surfaces. Its main use, so far, has been to sum up the extent of articular involvement without reference to degrees of joint inflammation or destruction, in other words, to express the "spread" of the disease. To use the Articular Index, one writes down the numerical value (instead of the name) of each affected joint as given in Table II (overleaf). The figures are added and a decimal point is placed before the last digit. Since the total peripheral joint surface is approximately $1,000 \mathrm{~cm}^{2}$. (or 0.1 sq. m.), this gives the percentage of total possible joint involvement, and is the Articular Index. (For purposes of charting both indexes on the same graph paper, the articular index may be multiplied by a factor of 3 to bring it to a scale comparable with that of the Systemic Index.)

Theoretically Table II can be used to sum up a variety of joint findings. It is possible, for instance, to assess the amount of progressive destruction at yearly intervals as determined by $x$ ray, provided satisfactory end-points can be agreed on. The Table has also been used to assess total lost motion in terms of "degrees lost per square centimetre of joint surface". This is a highly accurate but very 
TABLE II

ARTICULAR INDEX

Peripheral Joint Sizes Expressed in Terms of Souare Centimetres of ARTiculating Surfaces

TABLE FOR SUMMING UP JOINT FINDINGS

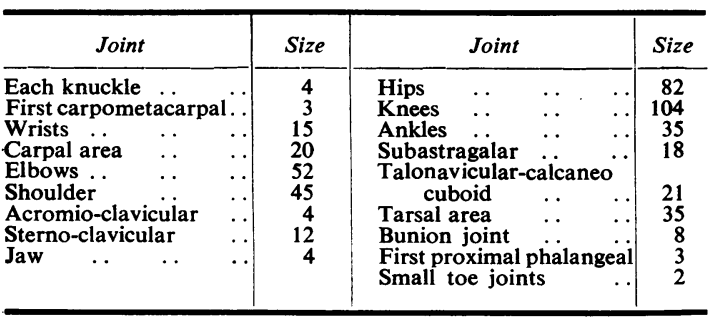

Reprinted, by kind permission of Lea and Febiger, from the American Journal of the Medical Sciences, 232, 152 (1956). with the following modifications: Finger and toe joints have been reduced to average figures of 4 and 1 respectively; carpal area now includes carpo-metacarpal joints; tarsal area now includes the tarsometatarsals.

Sample Calculation

\begin{tabular}{l|c}
\hline Joints Involved & Size in $\mathrm{cm} .^{2}$ \\
\hline 8 knuckles & 32 \\
2 carpal areas & 40 \\
1 wrist & 15 \\
2 elbows & 104 \\
1 knee & 104 \\
\hline \multicolumn{1}{c|}{ Total } & 295 \\
\hline
\end{tabular}

Articular Index is Sum (295) divided by $10=29 \cdot 5$ per cent. $=$ Percentage of total possible involvement.

tedious way of determining total articular function.*

In determining the simple "spread" of the disease, we have, so far, used as our end-point any objectively observable evidence of clinically active arthritis irrespective of its intensity. This end-point perhaps needs to be more clearly defined. If gradations in joint "activity" can ever be accurately quantitated (which we doubt), the Articular Index may take its place with the Systemic Index as a measure of "activity".

Preliminary, retrospective studies of the present, simple Articular Index in relation to the Systemic Index have yielded some interesting results. A comparison between eighty random pairs of Systemic and Articular Indices indicated a fair correlation $(r=0.78)$ as might be expected. Since the two indices measure quite different things, this is good supporting evidence for the accuracy of the Systemic Index through its full range of values. A subsequent comparison of charts showing the trends of both indices over long periods of time in fifteen patients has revealed a striking parallelism in ten cases.

\footnotetext{
* Evaluation of total lost joint motion on eleven ambulatory patients in our clinic by Miss Emily E. Mueller, R.P.T., M.S., gave figures ranging from 30.3 to 53.0 per cent. While this agreed fairly
well with our impression of the functional status of the patients, we did not feel that it justified the effort involved. Perhaps functional status is better gauged by qualitative methods.
}

These findings suggest that in some cases the overall activity of rheumatoid arthritis is well related to the total amount of inflamed joint tissue, irrespective of the degree of that inflammation. This may perhaps partly explain the difficulty experienced in trying to estimate the activity of the disease on the basis of grades of joint inflammation. A long-range, forward-going study of the relation of the Systemic Index and the Articular Index, with meticulous methods of joint evaluation, is needed to clarify this point.

The indices, when taken together, give us most of the information we need concerning a rheumatoid patient. However, they do not take into account certain very important items relating to the stage of the disease, such as local or general muscle atrophy, rheumatic nodules, etc. These are probably best kept in a separate category such as in the present American Rheumatism Association scheme.

\section{Conclusions}

In our hands the Systemic and Articular Indices have proved most useful in following the monthly progress of cases. But we do not as yet know the range of their applicability in other hands. We have therefore written this summary of our previous papers (Lansbury, 1956; Lansbury and Haut, 1956e Lansbury and Free, 1957), explaining them so thas they can be more widely tested.

Pilot studies, using one or both indices as a drug testing method, have already been completed by Bepler and Rogers (1957), Cohen and Calkins (1957), and Smyth and Clark (1957). Our indices were originally designed for drug-testing on a multiclinic scale. The preliminary reports indicate that they are quite useful for this purpose.

We suggest that those who try the Systemic and Articular Indices should withhold judgment as to their value until they have used them for at least a year and have been able to see for themselves the strikingly different course of cases attaining a ful clinical remission compared with cases in which the disease remains essentially unchanged. To be fully appreciated it is important to chart the indices month by month on ordinary graph paper.

Further studies needed in the field of evaluation include the following:

(1) Studies of inter-observer reliability in eliciting the items comprising the Systemic Index.

(2) Comparative studies of inter-observer reliability in grading joint inflammation. (This now constitutes the main basis for the present American Rheumatism Association grades of therapeutic response.) 
(3) Improvement of the Systemic Index, particularly by weighting those items now in use. (We should be most grateful to receive serial data on patients going into a full clinical remission in order to make up the number of cases needed for weighting by statistical methods.)

No system for evaluating rheumatoid arthritis should be accepted merely because it is plausible. Its reliability should first be statistically determined and its practicability should be tested in many clinics, and preferably, in more than one country.

\section{Summary}

In this article the author sums up previously published accounts of the successive steps which have led to the introduction of the Systemic Index and the Articular Index as measures of the activity of the rheumatoid process and the extent of joint involvement. Explicit directions for applying these new methods of evaluation are given so that they can be more widely tested. The two indices, taken together, supply most of the information which is needed in dealing with rheumatoid patients, and, when graphed at monthly intervals, permit the progress of each case and the response to therapy to be seen at a glance. The indices have also proved useful in assessing therapeutic response in groups of patients and should therefore be well suited to trials of new drugs.

\section{REFERENCES}

Bepler, C. R., and Rogers, F. B. (1957). Paper read at Philadelphia before the Post-Convention Tour, IX International Congress on Rheumatic Diseases. (To be published.)

Cohen, A. S., and Calkins, E. (1957). Paper read before the IX International Congress on Rheumatic Diseases, Toronto, June, 1957.

Lansbury, J. (1956). Amer. J. med. Sci., 231, 616; 232, 8 and

12; 232, 300.

- and Haut, D D. (1956). Ibid., 232, 150.

Mainland, D..(1956). Unpublished statistical study.
Smyth, C. J., and Clark, G. M. (1957). Paper read before the IX International Congress on Rheumatic Diseases, Toronto, June, 1957. (To be published.)

\section{Méthode numérique d'évaluer l'état de l'arthrite rhumatismale}

\section{RÉSUMÉ}

Dans cet article l'auteur résume les travaux précédemment publiés concernant les étapes successives qui ont conduit à l'introduction de l'Indice Général (en anglais systemic $=$ de l'organisme entier) et de l'Indice Articulaire comme mesures de l'activité du processus rhumatismal et de l'étendue de la lésion articulaire. On donne des instructions explicites pour appliquer ces nouvelles méthodes d'évaluation de façon qu'on puisse les essayer sur une plus grande échelle. Les deux indices, pris ensemble, fournissent la plus grande partie des renseignements dont on a besoin chez les malades rhumatismaux, et leur représentation graphique, de mois en mois, permet de se rendre compte d'un coup d'oeil des progrès de chaque cas et de leur réponse à la thérapie. Ces indices se sont aussi révélés utiles pour évaluer la réponse thérapeutique dans des groupes de malades et, par conséquent, ils devraient se prêter très bien à l'essai de nouveaux médicaments.

\section{Método numérico para valorar el estado de la artritis reumatoide \\ SUMARIO}

En este artículo el autor recapitula los trabajos publicados anteriormente respecto a los pasos sucesivos que condujeron a la introducción del Indice General (del organismo entero) y del Indice Articular como medidas de la actividad del proceso reumático y de la magnitud de la lesión articular. Se presentan instrucciones explícitas para aplicar estos nuevos métodos de valoración con el fin de facilitar su ensayo en mayor escala. Ambos índices, en conjunto, ofrecen la mayoría de los datos que se necesitan respecto a enfermos reumáticos y su representación gráfica, a intervalos de un mes, permite la observación fácil del progreso de cada caso y de su respuesta terapéutica. Estos índices revelaron también su utilidad en la valoración de la respuesta terapéutica en grupos de enfermos, se prestan pués a ensayos de nuevos medicamentos. 